\title{
A PROPOSTA POLÍTICA DE RUY FAUSTO
}

\author{
Leonardo Octavio Belinelli de Brito ${ }^{l}$
}

\begin{abstract}
RESUMO: Trata-se da resenha de Caminhos da esquerda - elementos para uma reconstrução, de Ruy Fausto (Companhia das Letras, 2017). Em sua primeira parte, a resenha faz uma caracterização geral da estrutura e da argumentação do livro, ambas centradas naquilo que o autor designa como "patologias da esquerda". Em seu segundo momento, a resenha examina a proposta política avançada por Fausto.
\end{abstract}

PALAVRAS-CHAVES: Esquerda; Teoria Política; Brasil contemporâneo.

\section{THE POLITICAL PROPOSAL OF RUY FAUSTO}

\begin{abstract}
This is the review of Caminhos da esquerda - elementos para uma reconstrução, by Ruy Fausto (Companhia das Letras, 2017). In its first part, the review gives a general characterization of the book's structure and argumentation, both centered on what the author calls "left pathologies". In its second moment, the review examines the political proposal advanced by Fausto.
\end{abstract}

KEYWORDS: Left; Political Theory; Contemporary Brazil.

Embora sejam muito diferentes entre si, é de se notar que um dos traços que distingue as figuras mais eminentes do Departamento de Filosofia da Universidade de São Paulo (USP), formadas entre os anos 1950 e 1970, é a sua atuação pública. É incontestável que pensadores

${ }^{1}$ Doutor em Ciência Política pela Universidade de São Paulo (USP). Pesquisador associado do Centro de Estudos da Cultura Contemporânea (CEDEC). E-mail: belinelli.leonardo@gmail. com 
como José Arthur Giannotti, Marilena Chauí, Ruy Fausto, Paulo Arantes, entre outros, tiveram e têm grande relevância no debate político brasileiro. Em estudo futuro, caberia refletir sobre as razões pelas quais um departamento universitário que almejava produzir professores de Filosofia profissionalizados do tipo francês (ARANTES, 1994) acabou indo além de seu objetivo inicial. Seja como for, o engajamento desses intelectuais continua rendendo frutos. Um deles é Caminhos da esquerda, de Ruy Fausto.

A mais recente publicação de Fausto é notável em vários sentidos. Salvo melhor compreensão, o livro deve ser lido como a conjugação de duas orientações: por um lado, como obra de um pensador ligado à cena política contemporânea local e internacional; por outro lado, como a culminação de um programa de estudos que vem desenvolvendo nos últimos anos, como revela um de seus livros anteriores, $A$ esquerda difícil (2007). O resultado é um livro ambicioso, com traços de manifesto político, que busca oferecer elementos para a reconstrução da relação entre teoria e prática na esquerda contemporânea. Daí que o livro se movimente em planos radicalmente diferentes: vai da crítica a alguns aspectos do pensamento de Karl Marx, passa pela exposição da visão do autor sobre a história dos problemas políticos da esquerda, e chega até a análise do impeachment de Dilma Rousseff. Entre a análise da filosofia da história do marxismo e a atualidade, o livro passa também pela crítica aos valores e a figuras da direita. Esse programa seria urgente, pois, como nota o autor, a "direita está no ataque", tanto no nível internacional, como no local.

Seria uma tarefa de proporções consideráveis fazer uma análise de todos os planos em que o livro se coloca. Impõe-se, portanto, um recorte. Como o livro deixa claro que a preocupação mais imediata do autor é a cena política brasileira, vamos nos deter em suas análises e propostas referentes a ela.

O procedimento de Fausto é claro: fazer a crítica da esquerda, sem cair em um hiper-criticismo demolidor, para propor um programa político. De certa maneira, como veremos, o filósofo uspiano aposta na ideia de que uma espécie de crítica política às tradições da esquerda seria necessária para fundar o que chama de programa político de uma “esquerda independente” (cf. FAUSTO, 2017, 118). Nos termos do autor: 
Minha hipótese é a de que um eventual trabalho de reconstrução deve começar pela percepção de que, por diferentes razões e sob diferentes formas, vivemos nos últimos cem anos um período de alienação radical do projeto de esquerda em relação ao que ela representou na origem, e deveria continuar representando (FAUSTO, 2017, p. 15 grifo nosso).

A ambição do livro é revelada no trecho; afinal de contas, mais do que um estudo que visa apenas à conjuntura, o livro de Fausto almeja contribuir para uma esquerda que estaria há cem anos fora de sua rota. Feitas as contas, o leitor perceberá a relação, não casual, com a Revolução Russa de 1917. Para conjugar planos tão distintos, a crítica de Fausto é desdobrada em três momentos, expostos na seguinte ordem: uma análise das "patologias" da esquerda; uma crítica a alguns ideólogos contemporâneos da direita brasileira e uma defesa dos valores de esquerda.

Segundo Fausto, as "patologias" da esquerda seriam divididas em três tipos: o "neototalitarismo", o "reformismo adesista" e o "populismo". Sob o primeiro rótulo, Fausto agrega os simpatizantes das linhagens bolchevique, maoísta e castrista. É interessante observar que o autor especifica com clareza a quem se dirige: cita siglas de partidos e nomes de filósofos, além de mencionar frações do movimento estudantil universitário. Nessa crítica, fica patente o hiato temporal que sua crítica tenta unir; afinal de contas, parece haver certa desproporção entre a centralidade que o autor confere à essa patologia e o impacto efetivo desses setores, hoje minoritários. Feita em meados da segunda década do século XXI, essa crítica parece mais afim a um acerto de contas com os grupos atuantes nos anos 1960.

Já o "reformismo adesista" seria identificado com aqueles intelectuais e políticos que se posicionam em torno do ex-presidente Fernando Henrique Cardoso, líder do Partido da Social Democracia Brasileira (PSDB). Sua marca seria a adesão ao capitalismo, embora permaneçam se situando à esquerda. Em tensão com seu postulado, o filósofo uspiano aponta que "ele [o reformismo adesista] não se situa mais na esquerda 
nem se pretende como tal." (FAUSTO, 2017, p.29). Mesmo que se tenha em mente o fato de que se trata de um grupo que iniciou sua trajetória política na esquerda e, progressivamente, a deixou de lado em favor de posturas simpáticas à liberalização econômica, talvez não seja adequado trata-lo como pertencente à esquerda, razão pela qual suas "patologias" também não seriam referente a esse campo político.

Por fim, surge a crítica do "populismo". Como essa é a patologia mais forte da qual sofreria a parte mais significativa da esquerda brasileira, Fausto a explora com mais vagar. Nesse caso, a análise é feita em dois movimentos: define o que é populismo e qual é o tipo de populismo que seria típico do Partido dos Trabalhadores (PT). No essencial, a definição de populismo adotada pelo autor é composta por três variáveis: liderança carismática; conciliação de interesses de classes antagônicas e certo "laxismo" na administração pública. Entretanto, para Fausto, seria possível falar de populismo em duas circunstâncias: quando essas três características estivessem presentes ou quando uma delas está ausente, mas as duas outras "sejam suficientemente marcados" (cf. FAUSTO, 2017, p.29). Embora não autoritário, o P'T representaria o populismo por combinar as três características assinaladas, do que resultaria o que Fausto chama de "populismo sui generis" (cf. FAUSTO, 2017, p.31).

O problema que o autor aponta com mais intensidade em sua crítica ao PT é justamente o da corrupção; ou melhor, o fato de que o PT teria aderido a um sistema corrupto, o que significaria que o partido teria recaído em uma "prática patológica comparável, mutatis mutandis, à política dos neototalitários e dos reformistas-adesistas." (idem, p.30). O ponto central da argumentação de Fausto não está em negar eventuais aspectos positivos das gestões petistas, mas sim em criticar aqueles que defendem (ou ignoram) a tese de que o PT só conseguiu fazer o que foi feito por ter aderido ao sistema corrupto. O raciocínio é claro e consistente: “Que o sistema político brasileiro seja visceralmente corrupto não absolve o PT. Poderíamos até mesmo dizer: é normal que a direita nade na corrupção, mas toda esquerda séria é infensa a esse tipo de coisa." (FAUSTO, 2017, p.31). Para o autor, o raciocínio de que o PT fez o que tinha que ser feito trouxe consequências catastróficas: "uma direita em plena ofensiva, uma 
esquerda golpeada e, de certo modo, desmoralizada, um país em amplo retrocesso político.” (FAUSTO, 2017, p.32). É a partir desse prisma que Fausto critica sua colega Marilena Chauí, pensadora que representaria essa posição acrítica em relação ao partido. Em contraste, o autor enxerga traços positivos em frações do Partido Socialismo e Liberdade (PSOL) e dos movimentos estudantis dos secundaristas, os quais teriam como horizonte um programa democrático e anticapitalista.

O arsenal das críticas de Fausto ao PT é variado, e não raro sólido. Entretanto, parece ter como fragilidade principal a falta de análise do sistema político no qual este partido atua. Em outras palavras: para efeitos de raciocínio e para além de eventuais injustiças cometidas por juízes e acusadores, pode-se aceitar sem muitas dificuldades o argumento de que o PT cometeu erros que resultaram, ao menos de modo parcial, no cenário político atual , como a questão do chamado escândalo do "mensalão", ocorrido entro 2005-6 e julgado em 2012, uma das razões para o fortalecimento da direita nas ruas em junho do ano seguinte. Porém, tais desvios devem ser compreendidos à luz de outra questão: como as ações do PT se vincularam às estruturas políticas corruptas sobre as quais teve que atuar? Ao desconsiderar essa questão, a crítica de Fausto corre o risco de cair em uma espécie de voluntarismo, segundo o qual o PT teria se tornado um partido corrupto porque seus dirigentes assim quiseram. Pode até ser que isso seja verdade, mas essa afirmação só poderia ser feita de modo consistente caso a estrutura político-partidária fosse analisada e se chegasse à conclusão, ao que parece inverossímil, de que ela não influía no comportamento ético de seus atores.

A combinação entre a urgência com a qual o livro foi escrito e a tentativa de especificação impacta o plano analítico e formal do livro, o que talvez seja inevitável. Isso fica especialmente claro no uso frequente que Fausto faz de prefixos ou outros qualificativos. Por exemplo, existem referências abundantes a termos como "neototalitarismo", "semiextrema esquerda", "populismo sui generis" etc. Por um lado, esses usos denotam uma tentativa de tentar articular fenômenos contemporâneos às categorias clássicas da teoria política, o que deve ser saudado por mostrar a vitalidade da disciplina. Por outro lado, a falta de profundidade nas explicações 
teóricas acerca dos fundamentos dessas qualificações deixa, por vezes, a sensação de que o raciocínio é movido por objetivos, ou critérios taxionômicos. Embora esse não seja o caso, o que nos interessa observar com essa ponderação é que a conjugação entre intenção política e reflexão teórica impacta na própria forma do livro, que parece relativizar a própria posição construtiva do autor, uma vez que cria a sensação de que ele se coloca, em certos momentos, como uma espécie de juiz da esquerda.

Depois dessas considerações críticas sobre a esquerda, surge o programa político de Fausto, o qual se baseia numa espécie de crítica política imanente às patologias mencionadas. Seus pilares são quatro: democracia (oposto ao neototalitarismo e ao populismo); anticapitalismo (contrário ao adesismo e ao aspecto conciliador do populismo), ética na administração pública (em contraposição ao laxismo proporcionado pelo populismo) e ecologia (em contraste à destruição da natureza promovida pelo capitalismo e pelo "socialismo de caserna”). Como esse é o centro da proposta do livro, vale nos aprofundarmos.

Renomado estudioso da obra de Karl Marx, Fausto é claro ao afirmar que a sua perspectiva é, em certa medida, contrária à do filósofo alemão. Em primeiro lugar, porque abandona o comunismo como horizonte, uma vez que ele teria se tornado "utópico" e perigoso, pois os regimes que invocaram essa modalidade de regime sócio-político acabaram totalitários (cf. FAUSTO, 2017, p.95). Em contraste com esse suposto utopismo, Fausto propõe "conservar o dinheiro e uma forma de mercado, mais o Estado e a propriedade privada, ainda que não de todo tipo de bens." (FAUSTO, 2017, p.95). Daí que o autor busque atualizar as críticas de Marx em três dimensões: antropológica, histórica e econômica. Todavia, uma operação dessas dificilmente pode ser feita em vinte páginas, como pretende o livro. A filosofia da história de um autor como Walter Benjamin é despachada em poucas linhas, enquanto o livro consome catorze de suas páginas para analisar a retórica de intelectuais do baixo escalão da direita brasileira. A desproporção dos assuntos e dos intelectuais tratados sinaliza, uma vez mais, as dificuldades da forma do livro.

Seja como for, chama a atenção a busca de Fausto por fazer propostas precisas. Isso fica claro, por exemplo, quando é explicada 
sua proposta a respeito da democracia: trata-se de uma defesa da democracia representativa - e, portanto, crítica das críticas da esquerda à representação - pois, apesar dos pesares, ela se basearia na igualdade, enquanto o capitalismo teria como suposto a desigualdade. Entretanto, em que pese a argumentação do autor, fica difícil entender a razão pela qual essa contradição poderia levar à superação da ordem existente, na medida em que democracia representativa e capitalismo são combináveis - como, aliás, o próprio autor reconhece. Ou seja: a conjugação de igualdade formal (direitos civis e políticos) e mesmo o avanço social (direitos sociais) pode ser uma ferramenta que, embora contradiga a desigualdade propiciada pelas diferentes inserções econômicas das classes no sistema capitalista, serve como fonte de legitimação dessa desigualdade, uma vez que cria a sensação de que os indivíduos partem de pontos de partida similares. Com essa observação, não se trata, entretanto, de desprezar a democracia como uma forma de "ideologia burguesa", mas de apontar que o vínculo entre capitalismo e democracia comporta nuances as quais valeria a pena examinar. Um exemplo dessa nuance é o fato de que o "reformismo adesista", segundo o raciocínio de Fausto, é simpático ao capitalismo e democrático. Trata-se, portanto, de indicar que uma proposta de reconstrução da esquerda demanda o tratamento mais aprofundado da crítica do capitalismo e de suas formas políticas contemporâneas, tema infelizmente deixado de lado por Fausto no livro. Sem ela, a busca pelas propostas concretas do autor não elimina a sensação de que seria preciso ir mais longe na explicação.

O mesmo acontece quando Fausto esclarece que sua defesa do “anticapitalismo" não significa crítica radical ao Estado, nem à propriedade privada dos meios de produção.

No meu entender, o objetivo da política de esquerda deve ser a neutralização do capital, tanto extensiva quanto intensivamente (ele não pode entrar em qualquer lugar e o seu peso tem que ser limitado). É o grande capital que se tem em mira. Mas não se pense que esse projeto é simplesmente "reformista". O capitalismo não existe sem o grande capital. (FAUSTO, 2017, p. 41, grifos nossos). 
Sem negar a pertinência da observação, poder-se-ia indagar: o "pequeno capital" também não faria parte da lógica do capital? Não seria razoável imaginar que o "pequeno capital", por meio da lógica da acumulação, se converte em "grande capital”? Um não levaria ao outro? Se não, por quê?

A ojeriza de Ruy Fausto pela violência do totalitarismo, resulta na sua rejeição do caminho revolucionário clássico. Dessa veemente recusa, entretanto, surge a sensação de que há certa tensão no argumento do autor: por um lado, trata-se de propor um programa de reformas fortes sem violência; ora, esse programa não seria visto pelos defensores $\mathrm{da}$ ordem como sendo ele mesmo violento? Para tanto, basta ter em conta a rejeição em bloco da parcela dominante brasileira pelo programa "lulista", notoriamente conciliador (SINGER, 2012; SINGER, 2018). Em comparação, o programa de Fausto parece estar, em mais de um sentido, à esquerda do lulista, mas, ao mesmo tempo, parece conter uma resistência similar (ou maior) ao conflito que o programa petista.

Essa impressão surge tanto da falta de profundidade das análises do autor sobre os governos petistas, como da sua constante denúncia da violência da esquerda e da direita. Por essa via, retomamos uma observação feita antes: se Fausto tem razão em apontar a plêiade de equívocos do PT em seus governos, bem como em criticar a violência política de setores da esquerda e da direita brasileira, falta-lhe entrar no debate sobre as possíveis possibilidades que esse partido teve (ou não) em seus governos e desperdiçou, do que deriva a necessidade de analisar a organização do conflito político no Brasil. Nesse sentido, seria preciso analisar como o desvirtuamento do PT tem relação com a estruturação do sistema político e do capitalismo brasileiro. É difícil crer que isso se deva apenas aos erros morais de suas lideranças, embora esses existam.

Assim, até onde pudemos perceber, as dificuldades teóricas e formais do livro são oriundas, em parte, do seu caráter misto de manifesto, reflexão conjuntural e reflexão mais profunda. Cabe destacar também o contexto difícil em que essas reflexões foram escritas. Diante disso, como obra teórica e política, o livro de Fausto deve ser saudado pelo empenho reflexivo em articular dimensões externas e internas, bem como o passado, 
o presente e o futuro. É um importante ponto de partida, que deve ser desdobrado. Tarefa que cabe aos simpatizantes de seu programa.

\section{REFERÊNCIAS BIBLIOGRÁFICAS:}

ARANTES, Paulo. Um departamento francês no ultramar. São Paulo: Paz e Terra, 1994.

FAUSTO, Ruy. Caminhos da esquerda. São Paulo: Companhia das Letras, 2017.

SINGER, André. Os sentidos do lulismo. São Paulo: Companhia das Letras, 2012.

SINGER, André. O lulismo em crise. São Paulo: Companhia das Letras, 2018.

Texto recebido em 28/11/2018 e aprovado em 10/06/2019 
